\title{
Gender-Based Violence in Moroccan Folktales
}

\author{
Fatima Zahra Touzani \\ Department of English \\ Faculty of Arts and Humanities \\ Sultan Moulay Slimane University, Beni Mellal, Morocco \\ Email: fattouzani@gmail.com
}

Received: 9/12/2021 Accepted: 10/6/2021 Published: 10/24/2021

\begin{abstract}
Men in Morocco have always employed many strategies whereby they have established their domination over women. Their patriarchal tendencies have proven incommensurable with the discourse of wisdom they purport to advocate. Accordingly, they have had to concoct elaborate stories and excuses to actualize their proclivities. Patriarchal hegemony has manifested itself in different ways and resulted in many phenomena, the most influential of which is undoubtedly violence against women that is predominant in the domestic sphere and the public sphere. This omnipresence accentuates through its portrayal in popular culture, including proverbs and folktales. Since folktales encapsulate a culture's inherited customs, traditions, and values, this article's primary concern is to investigate whether Moroccan folktales represent the logic dictated by Moroccan patriarchal institutions, aiming at reinforcing the oppression of women through violence. Specifically, the article seeks to address the representations of violence against women in folktales collected by Inea Bushnaq and Malika El Ouali Alami. The findings in this article prove that Moroccan folktales validate the Moroccan cultural norms that highlight the position of women as subordinate characters ready to follow the rules of patriarchal institutions. A recurrent theme throughout these tales is Gender-Based Violence. Thus, this article attempts to demonstrate the representations of GBV in Bushnaq's and Alami's tales.

Keywords: gender-based violence, Moroccan folktales, Arab Folktales by Inea Bushnaq, Kan Ya Ma Kan: Moroccan Folk Tales on Women by Malika Alami
\end{abstract}

Cite as: Touzani, F. Z. (2021). Gender-Based Violence in Moroccan Folktales. Arab World English Journal for Translation \& Literary Studies 5 (4) 46-59.

DOI: http://dx.doi.org/10.24093/awejtls/vol5no4.4 


\section{Introduction}

This article focuses on the representations of gender-based violence in Moroccan folktales. The main objective is to interrogate the question: do Moroccan folktales represent the logic dictated by Moroccan patriarchal institutions that aim to reinforce women's oppression through violence? Notably, the article seeks to address issues about the representations of violence against women in two collections of Moroccan folktales. The first collection, Arab Folktales, is translated and edited by Inea Bushnaq (1986). The second collection, Kan Ya Ma Kan: Moroccan Folk Tales on Women, is translated by Malika El Ouali Alami (2013). While the first one contains twenty-three Moroccan tales, the second one encompasses eleven tales. One of the main themes throughout these tales is GBV. Therefore, this article will investigate the representations of GBV in a selection of these tales.

Two essential reasons induce interest in the representations of gender-based violence in Moroccan folktales. Firstly, folktales, like proverbs, encapsulate a culture's customs, traditions, values, and overall, wisdom. Yet, most Moroccan folktales seem to be employed to serve Moroccan patriarchal institutions whose ideology strengthens the subordinate position of women, a position marked by various forms of oppression, the most obvious of which is gender-based violence. Secondly, Moroccan folktales seem to validate the cultural norms dictated by Moroccan patriarchal mindsets, norms that epitomize the oppression of women through violence.

Before delving into the representations of gender-based violence in Moroccan folktales, the first part of the article intends to provide the theoretical framework of the research. For this reason, the researcher will divide this part into two sections. The first section will be devoted to genderbased violence, whereas the second one will be dedicated to folktales and their functions.

\section{Literature Review \\ Gender- Based Violence}

Feminism has played an essential role in shedding light on gender-based violence. Mackay (2021) has argued that feminist theory, "and particularly Radical Feminist theory, has given us the promise that commonplace though these crimes may be normal or natural they are not" (p. 4). Western, a feminist, (2013) has focused on the short-term and long-term impacts of gender-based violence against women. She has mentioned "depression" (p. 3) as a critical effect.

The United Nations General Assembly (1993) has defined violence against women as “any act of gender-based violence that results in, physical, sexual or psychological harm or suffering to women, including threats of such acts, coercion or arbitrary deprivations of liberty, whether occurring in public or private life"' (p. 1). Violence can touch the body as it can touch the psyche of women. Yet, if physical wounds may take a short time to heal, psychological ones may be eternal.

The UN's definition elucidates that the violence meted out to women is multitudinous and has immediate as well as everlasting physical and psychological effects that, in many cases, may mar their future with perennial scars. These scars stem from several forms of violence, all of which abuse women's fundamental rights and attempt to marginalize them and hinder their progress. To 
grant this objective success, patriarchal institutions try various forms of oppression to deprive women of their fundamental rights.

As the definition clarifies, gender-based violence can be physical, sexual, or psychological. For the sake of examining the characteristics of each kind, the researcher will divide this section into three parts, each of which will deal with one type of gender-based violence.

\section{Physical Violence}

The first manifestation of gender-based violence is physical. Physical violence involves causing an injury, also known as physical trauma, to the body through bodily contact. Physical violence may include "slapping or throwing something that could hurt an intimate partner" (Meurens \& Spanikova, 2017, p. 31). Physical violence may also comprise "pushing, shoving, pulling hair .... hitting with a fist or anything else that could hurt an intimate partner .... kicking, dragging or beating up .... intentional choking or burning, and threatening to use a gun, knife or [another] weapon against an intimate partner" (Meurens \& Spanikova, 2017, p. 31).

Physical violence is related to whatever can harm the female body, such as hitting, dragging, beating up, kicking, or burning. These manifestations of physical violence demonstrate that one can find this kind in many types of violence against women. For example, sexual violence may involve physical violence in the case of rape. Economic violence, another dimension of violence, may involve physical violence if forcefully "stopping or preventing an intimate partner from working" (Meurens \& Spanikova, 2017, p. 31). Thus, physical violence may be considered a cornerstone of violence against women, for its impact on women can be easily recognized.

Physical violence harms the female body as it may result in "abdominal/thoracic injuries," "bruises and welts," "chronic pain syndromes," "disability," "fibromyalgia," "fractures," "gastrointestinal disorders," "irritable bowel syndrome," "lacerations and abrasions," "ocular damage," and "reduced physical functioning" (Krug, Dahlberg, Mercy, Zwi \& Lozano, 2002, p. 101). Due to this plethora of consequences, physical violence against women can be considered the most noticeable type. It is so because it affects both the body and the psyche of the victim. The victim finds herself obliged to deal with outward physical injuries and deep psychological wounds.

\section{Sexual Violence}

The second kind pertains to sexual violence, which indicates abuse in its different forms. As Krug et al. (2002) elucidate, this type of violence refers toany sexual act, attempt to obtain a sexual act, unwanted sexual comments or advances, or acts to traffic, or otherwise directed, against a person's sexuality using coercion, by any person regardless of their relationship to the victim, in any setting, including but not limited to home and work. (p.149)

Sexual violence is not limited to sexual acts, for one can classify any endeavor to get them as violence. Also, it does not matter who is involved in such violence, as the perpetrator can be anyone regardless of the kind of relationship between the victim and the offender. 
Though sexual violence refers basically to rape, it can encompass other forms of assault. Krug et al. (2002) mention eleven forms: "rape within marriage or dating relationships," (p.149) "rape by strangers," (p. 149) "systematic rape during armed conflict," (p. 149) "unwanted sexual advances or sexual harassment, including demanding sex in return for favors," (p. 149) "sexual abuse of mentally or physically disabled people," (p. 149) "sexual abuse of children," (p. 149) "forced marriage or cohabitation, including the marriage of children," (p. 149) "denial of the right to use contraception or to adopt other measures to protest against sexually transmitted diseases," (p. 149) "forced abortion," (p. 149) "violent acts against the sexual integrity of women," (p. 150) and "forced prostitution and trafficking of people for the purpose of sexual exploitation" (p. 150).

These various forms imply that sexual violence does not refer to a particular form of abuse. Diverse sexual violence forms occasionally emerge. Though the new forms vary, the idea of forcefully invading the victim's sexual intimacy through coercion is a common characteristic. Sexual violence has been, in fact, the most notorious type of gender-based violence since it may result in many consequences such as "gynecological disorders," "infertility," "pregnancy complications/miscarriage," "sexually transmitted diseases, including HID/AIDS," "unsafe abortion," and "unwanted pregnancy" (Krug et al., 2002, p. 101).

\section{Psychological Violence}

Psychological violence is another primary type of gender-based violence. Though not visible and may stay covert for years, psychological violence can be as ravaging as physical violence. Meurens \& Spanikova (2017) define this type of violence as any "act or behavior which causes psychological harm to the partner or former partner. Psychological violence can take the form of, among others, coercion, defamation, a verbal insult or harassment" (p. 45). In this way, it may affect the victim's psychological stability and mental sanity. No wonder, then, that The Istanbul Convention defines it as "intentional conduct of seriously impairing a person's psychological integrity through coercion or threats" (Meurens \& Spanikova, 2017, p. 46). Conspicuously, this type involves the perpetrator's intention to harm the victim's psychology using different tools. This results in shaking the victims' psychological integrity.

Due to its seriousness, psychological violence can result in various health consequences that entail this type's profound, and probably permanent impact. Thus, female victims may experience "alcohol and drug abuse," "depression and anxiety," "eating and sleep disorders," "feelings of shame and guilt," "phobias and panic disorder," "physical inactivity," "poor self-esteem," "posttraumatic stress disorder," "psychosomatic disorders," "smoking" and "suicidal behavior and selfharm" (Krug et al., 2002, p. 101).

Indeed, the victim's psyche becomes entangled in a great web of horror, a web marked by lasting scars reminiscent of the brutality of the perpetrator's behavior. Physical blisters or wounds may be healed and may disappear, but psychological ones stick to the mind and the victim's heart. In most cases, victims of psychological violence need medical assistance to help them get rid of the nightmarish consequences of the frightening experiences they have gone through. 
This overview illustrates that gender-based violence is a real affliction whose various forms, manifested in physical, sexual, and psychological violence, torment female victims in numerous ways. Female victims' torture is not limited to their bodies that suffer tremendously from male oppression and atrocity, but covers their intimacy and psyche, both of which are enormously affected.

Though much has been written about violence against women in general and Moroccan women in particular, including physical, sexual, and psychological violence, no published research has addressed gender-based violence in Moroccan folktales. This domain remains a fertile ground for exploration. Thus, this article is meant to fill in this literary gap and open up an avenue of research into gender-based violence in Moroccan orature.

\section{Functions of Folktales}

The eminent American anthropologist William Bascom (1912-1981) defines folktales as "prose narratives which are regarded as fiction. [Folktales] are not considered as dogma or history, they may or may not have happened, and they are not to be taken seriously" (1965, p. 4). Though there is no consensus on the historical veracity of these tales, and though "it is often said that they are told only for amusement, they have other important functions" (Bascom, 1965, p. 4). These functions prove the momentousness of folktales in recording the past, understanding the present, and foreshadowing the future.

Folktales function in various ways. This function can be didactic as it can be psychological or cultural. Bascom (1954) argues that folklore functions in four different ways: it amuses, validates culture, educates, and maintains conformity. To throw light on these functions, the researcher will divide this section into four parts, each of which will discuss one of Bascom's functions.

\section{The Psychological Escape}

Bascom cites "amusement/entertainment" as the first function of folktales. People retell stories because their lore entertains them. Amusement is, undoubtedly, an essential function of folktales, yet "it is apparent that beneath a great deal of humor lies a deeper meaning" (Bascom, 1954 , p. 343). What lies beneath is undoubtedly a deeper level of cultural, social, and educative dynamism.

The psychological escape offered by folktales can be manifested in enabling people to escape from a real harsh world characterized by frustration, biological, social, and cultural limitations to a virtual one replete with fantasy. While retelling stories, people imagine living in more appropriate conditions or escaping the constraints of life and death. These fantasies function as catharsis, for; first, they set free the tension enabling people to get rid of their feelings of fear and anxiety, and, second, they prepare them to be more tolerant and accept their life conditions despite whatever limitation they may face. In this manner, folktales offer a safe shelter that lets people escape from social repressions (Bascom, 1954).

Arab World English Journal for Translation \& Literary Studies 
Amusement is a vital function for many reasons. The most important reason is its capacity to release tension and provide people with better conditions found in a virtual world laden with fantasies. Folktales amuse as they provide a psychological escape from the brutality and the monotony of the daily.

\section{The Validation of Culture}

As they can amuse, folktales can also validate a culture. In this vein, Bascom (1954) contends that folktales validate certain cultural aspects and justify their institutions. "Explanatory tales," for example, or "moral animal tales" (p. 344) validate cultural institutions and warn of ensuing consequences in case of breaching standard practices. Such narratives serve as final references to questions of law, politics, society, and economy. They function to indoctrinate the community members from an early age with their community's religious, political, and ideological norms and values. In other words, folktales instruct people on how to live, what to believe in, how to behave, etc. Therefore, parents use such folktales to teach their children proper behavior and reproach potential offenders for making wrong decisions. Thus, each folktale highlights a specific cultural value related to the community it represents.

Accordingly, the second function of folktales has to do with stressing the importance of cultural values that characterize a society. It is a valuable function as it attempts to inculcate a sense of responsibility through retelling folktales. Rigorous attempts to instill discipline and good behavior through highlighting cultural values can validate culture and cultural values.

\section{Educative Function}

The third function is educative, as it deals with the listener's education in "non-literate societies" (Bascom, 1954, p. 345). Here, folktales fulfill a didactic function that illustrates the importance of specific values emblematic of a given culture. These cultural values are inherent components and pass from generation to generation thanks to this educative function.

In this context, folktales become pedagogic devices that strengthen ethics through propagating the wisdom of former generations. This takes place through imbuing moral values in students using a more entertaining method. Folktales can also fulfill a didactic function because their teaching varies from history to cultural norms, to assiduousness, deference, etc. Legends can also fulfill this didactic function because their defining features qualify them to explain the existence of things or their general traits (Bascom, 1954).

Education is therefore labeled of paramount importance since it communicates ideas and boosts the attitudes of the members of society. Education remains predominantly significant due to its contribution to demonstrating the importance of outstanding cultural values.

\section{Conformity to Cultural Norms and Patterns of Behavior}

Conformity to cultural norms is the last function of folktales, according to Bascom (1954). This function, though often neglected, is of enormous importance because it takes care of perpetuating conformity to standardized patterns of behavior one expects to find among members of a community. 
This function is related to teaching appropriate ways of acting and living. A family can choose a relevant tale to teach the proper behavior or to rebuke someone for making wrong decisions tacitly. Thus, one can use these folktales to check on attitudes to advocate conformity to cultural norms and values. In this way, folktales champion the status quo and try to keep it in order. Folktales serve the task of applying cultural norms and behavior patterns. This implies a kind of cohesion among the members of the group. Conforming to the binding norms of the culture reinforces this cohesion (Bascom, 1954).

Therefore, one can sum up the fourth function to stand for social approval and disapproval. On the one hand, one can use folktales to highlight the right attitude that conforms to cultural forms. On the other hand, one can employ them to denounce unwanted behaviors.

These four functions clarify the tremendous importance of folktales in entertaining, validating cultural values, educating the group members, and punishing in case of non-conformity to cultural norms and behavior patterns. These functions describe the colossal significance of folktales in shaping the personality of a member of society. Group members have to comply with the teachings of their cultures that are conspicuously abundant in folktales.

\section{Data Presentation and Analysis}

Malika El Ouali Alami (2013) contends that folktales in Morocco are an intrinsic part of Moroccan orature. One can classify Moroccan folktales into four major categories: animal tales, marvelous tales, hagiographic tales, and comic tales.

Animal tales are the commonest in the Moroccan oral tradition because of their conciseness and simplicity. These tales are "used mainly for children but can also be used for adults to teach a moral lesson" (Alami, 2013, p. 9). The hedgehog and the wolf are the most recurrent animals in these tales. While the first epitomizes intelligence, the second embodies foolishness. Thus, the Moroccan oral tradition consistently portrays the hedgehog helping the wolf out of difficult situations. Other frequent animals are the lion, the horse, the pig, the donkey, the fox, the snake, the mouse, and frogs. These tales may also contain birds such as the stork, the pigeon, the crow, and the owl (Alami, 2013).

Marvelous tales deal with "magical world and creatures and wonderful events performed by genies or fairies as well as outstanding heroes whose human attributes acquire larger dimensions to suit the wonderful world in which they are set" (Alami, 2013, p. 10). The setting in marvelous tales switches from the human world to the supernatural world made of genies and ogres "with an ease that only the logic of tale-telling and the law of narration can regulate" (Alami, 2013 , p. 10). The plot in these tales revolves mainly around the idea of a quest that usually ends in triumph: the hero defeats the foe that can be either an ogre or a genie. Most marvelous tales depict the quest for a charming beloved and usually end in marriage (Alami, 2013).

Hagiographic tales deal with saints. They can be "either legends that folk imagination has woven around saints" to boost their "religious faith and power in performing prodigies, or realistic stories deriving from saints' real life and events that happened to them in their life illustrating their 
piety and devotion to God" (Alami, 2013, pp. 10-11). These events, like marvelous tales, are set in real and imaginary worlds as they oscillate between reality and fiction concerning the saint's deeds according to the folk imagination.

Comic tales are stories that involve humor as a predominant feature. They are "usually short and not as well-knit as marvelous tales on the narrative level" (Alami, 2013, p. 11). Comic tales comprise two or three characters, usually the woman, the Fakih, and the fool, and hinge on "socially rejected qualities like cunning, foolishness and laziness" (Alami, 2013, p.11). Though these tales provoke laughter throughout the plot, they criticize the previously mentioned rejected qualities through an implicit dexterous use of ridicule.

Researchers in Morocco and abroad have been interested in Moroccan folktales. Among these researchers are Bushnaq (1986) and Alami (2013). Both authors have collected Moroccan tales, some of which deal with the representations of women in oral literature. If Bushnaq's work deals with folktales in the Arab world, Alami's research is devoted to Moroccan tales on women. Within this framework, the researcher will dedicate the second part of this article to the analysis of the representations of women in both authors' collections. Notably, this part will delve into the representations of gender-based violence in Moroccan folktales collected by both Bushnaq and Alami.

\section{Gender-Based Violence in Moroccan Folktales Inea Bushnaq}

Inea Bushnaq, a Palestinian-American folklorist, published Arab Folktales in 1987. This book is a collection of 130 folktales from all over the Arab world. Bushnaq classified these tales into seven categories: "Bedouin Tales," "Tales of Magic and the Supernatural," "Magical Marriages and Mismatches," "Animal Tales," "Stories of Djuha and His Kind," "Religious Tales and Moral Instructions" and "Tales of Wit and Wisdom." Arab Folktales contains thirteen folktales from Morocco. These tales are titled "The Foreign Wife," "Successor to the Sheikh," "The Girl Who Banished Seven Boys," "The Bald Man at the Funeral," "The Boy Magician," "The Woodcutter without a Brain," "Two Close Calls," "Division of the Prey," "Souleyman and the Little Owl," "The Angel Wedding," "Djuha and the Hunter's Gift," "Bahlul and the Owl" and "The Boy Who Heard the Dew When It Fell." In this section, the researcher will investigate the representations of gender-based violence in Bushnaq's folktales.

The thirteen Moroccan tales collected by Bushnaq deal with different topics. This section will overlook those that are not related to the portrayal of gender-based violence. This analysis will leave out the five animal tales: "The Woodcutter without a Brain," "Two Close Calls," "Division of the Prey," "Souleyman and the Little Owl," and "The Angel Wedding." The analysis will also overlook the two comic tales titled: "Djuha and the Hunter's Gift" and "Bahlul and the Owl" in addition to the Bedouin tale titled "Successor to the Sheikh," for they do not fit the objective of the analysis. The three tales of magic and supernatural, titled "The Bald Man at the Funeral," "The Boy Who Heard the Dew When It Fell," and "The Boy Magician," will also be ignored for not meeting the objective of this article. Though this analysis will focus on two tales, they represent the other Moroccan tales that Bushnaq does not include in her collection. 


\section{The Foreign Wife Synopsis}

"The Foreign Wife" is a tale that traces the life of a Moroccan lady named Hamda from childhood to adulthood. This woman goes through various stages of violence throughout her life. Once Hamda, the daughter of a Bedouin prince, grew old enough "to be eyed as a woman," her father "pitched a tent for her apart, to hide her from the sight of men" (Bushnaq, 1987, p. 20). The father also "built a closed litter with windows in its sides so that Hamda could travel unseen whenever the camp was moved" (Bushnaq, 1987, p. 20).

Unfortunately, one day, while sleeping in her closed litter, Hamda's camel rose and walked away. When she woke up, she found herself far away. Prince Mohammad found her camel in the grazing grounds and immediately fell in love with her. He married her and left the two women he had married before. Years later, after the birth of her son Faris, the prince's former wives started planning to get the prince back. Their plan worked, and the prince got rid of Hamda and her son, deprived them of their fundamental rights, and brought back his old wives.

\section{Commentary}

This tale portrays Moroccan women as submissive creatures whose fate is to live on the margins of society. Hamda was exposed to gender-based violence as a teenager and as an adult. As a teenager, she was imprisoned in a tent. The tent may be said to stand for society's handcuffs that deliberately hamper women. Hamda is a beautiful lady, and her beauty endangers men. Thus, the only way to protect men is to push her to the periphery. Hamda is as obedient as a domesticated animal. She never revolts. Therefore, traveling in a "closed litter" does not make her stand against her father or criticize him. Indeed, her father's actions do not imply any intention to harm her in any way. On the contrary, his deeds are prompted by his desire to protect her. This desire suits the norms dictated by a patriarchal society that has always considered the female body a sexual object whose primary function is to quench men's desires. There is no physical violence in both actions, but there is psychological violence manifested in society's attempts to constrain women's freedom.

Hamda experiences another instance of psychological violence when her husband, the prince, abandoned her and went back to his old wives. This behavior proves that his claims of devotion were not genuine, and that his feelings towards her were fake. Yet, Hamda is not the only woman that suffers from psychological violence in this tale, for the prince's first wives went through the same experience after Hamda had altered their husband's heart. The prince left both wives after years of marriage due to falling in love with a beautiful lady. Thus the three women suffer in this tale: Hamda and the prince's first wives. While the first suffers twice: first at home owing to her father's decision to incarcerate her and second away due to her husband's decision to get rid of her, the second two wives suffer because their husband departed for the sake of new love.

These women's exposure to this kind of violence elucidates the overwhelming effect of a patriarchal mentality that resists change. This tale validates Moroccan cultural norms that highlight the position of women as obedient and passive figures. Women are unable to denounce the dictatorship of a patriarchal society because the same society brings them up thinking that the norm 
is to be subordinated and to remain silent. Thus, this validation functions through stressing the inferior position of women that tolerates all forms of violence, including the psychological one.

\section{The Girl Who Banished Seven Youths Synopsis}

"The Girl Who Banished Seven Youths" tells the story of seven brothers who left their mother alone after the birth of their sister, "Wudei'a Who Sent Away Subei'a." The seven brothers wanted to have a sister. Their wish was fulfilled as their mother gave birth to a girl. However, their aunt informed them that the baby was a boy. The youths did not like the idea of having a new brother; so, they left everything behind and "went off into the desert" (Bushnaq, 1986, p. 119). When the girl grew up, she left home to look for her brothers. She found them and, after a series of adventures in a magical world full of ogres, they returned home and lived in peace and happiness till they died.

\section{Commentary}

This tale depicts the atrocity of a patriarchal society whose institutions dictate the rules that govern it and which favors men over women. The tale's events confirm this, including the characters' names. The girl's name, Wudei'a, which means gentle in Arabic, epitomizes kindness and tenderness. Both words in Arabic refer to acquiescence. Women, therefore, are innately kind and should submit to men whose cruelty is their overwhelming characteristic. However, the boys' name, Subei'a, has different connotations as it refers to many things in Arabic. It may refer to number seven as it may stand for lion, the powerful, fierce animal known as the jungle king. If the name chosen by folk refers to the number seven, this choice connotes an implicit critique of Wudei'a. This interpretation connotes that her kindness is superficial since it results in banishing seven boys. If it relates to the jungle king, it connotes a potent metaphor that highlights the supremacy of men in Moroccan society. It is this inherent supremacy over women that grants men the upper hand.

The boys' departure has many consequences, the first of which is the mother's suffering. The mother, as a woman, cannot choose the gender of her child. Still, everyone blames her in this tale. Her sons leave her alone, thinking that she has given birth to another boy. This behavior breaks her heart and leads her to endure great grief and endless waves of yearning. This psychological violence exercised by her sons is worse than one exercised by an intimate partner. While a son is an integral part of his mother, a close partner remains a stranger after all.

The second impact concerns Wudei'a, for the poor girl, believed to be responsible for banishing her brothers, has to do everything possible to find her brothers and bring them back. She has to "search the world from its beginning to its end" to find them (Bushnaq, 1986, p. 120). To do so, Wudei'a goes through incredible physical and psychological hardships. On the one hand, she consents to the cruelty of the manservant and the maid whose nefarious intentions have deprived her of the camel and made her walk on the ground for a long distance. This resulted in bleeding. On the other hand, she has to deal with tormenting feelings of responsibility. What intensifies the girl's feelings of guilt is the affliction that has befallen her mother due to her birth.

Arab World English Journal for Translation \& Literary Studies 
Like the first tale, "The Foreign Wife," the second one validates Moroccan cultural norms that underline the inferiority of women in Morocco. Women in this tale, as in reality, are amenable and frequently exposed to different types of violence. The most palpable kind is undoubtedly psychological violence that manifests itself in ignoring women's psyche. Women are second-class citizens whose feelings are not as important as men's. Therefore, this validation operates through underscoring the subordinate status of women. This status is willing to countenance the cruelty of dominating male culture and surrender to each kind of violence.

Thus, both tales illustrate that Moroccan folktales collected by Inea Bushnaq encompass instances of violence against women. This violence is both physical and psychological. If one can quickly notice the first type, one needs more attention to observe the second. In addition, both tales seem to validate the Moroccan cultural norm that highlights the position of women as subordinate characters ready to follow the rules of patriarchal institutions that govern everything.

\section{Malika Elouali Alami}

Malika El Ouali Alami, a Moroccan translator and feminist, published Kan Ya Ma Kan: Moroccan Folk Tales on Women in 2013. This book is a collection of eleven Moroccan folktales. The book contains two parts: while the first one includes the tales in Arabic, the second one comprises the same tales translated into English. As the title implies, all the tales revolve around Moroccan women. These tales are the following: "Beautiful Almond," "The Two Sisters," "The Woman and the Arrogant Merchant," "Yetou and Her Step Mother," "The Learned Woman," "The Forsaken Daughter," "The Princess and the Rolling Ball," "Lalla Khullala Khadra," "Zriqa Mriqa," "Haina," and "The Merchant's Daughter." In this section, the researcher will explore the representations of gender-based violence in Alami's collection of folktales. Mainly, the analysis will cover "The Learned Woman" and "Beautiful Almond" because they represent Alami's collection.

\section{The Learned Woman Synopsis}

"The Learned Woman" tells the story of two orphan children, a boy and a girl. When the two grew up, the boy married, but his sister remained single. She devoted herself to learning. The man kept visiting his sister owing to their great love. However, he did not tell his wife about the relationship between him and the lady who preferred to live in a nearby house to see her brother regularly. After years of marriage, the wife discovered that her husband paid regular visits to that lady. Thinking that her husband was married to her, she convinced him to get rid of her. The husband claimed to take his sister for a picnic, but while out, he "took a knife from his pocket, cut off her two hands and abandoned her in the forest" (Alami, 2013, p. 30). After this incident, The Learned Woman endured various hardships, but her patience was rewarded, for she got back her hands, married the king, and together, they lived in happiness for the rest of their life.

\section{Commentary}

This tale demonstrates the conditions favorable for the imagining of a patriarchal society. Despite the strong relationship between the man and his sister, the tale presents an entirely different image of the loving brother. Most often, we encounter a brother portrayed as kind, supportive and 
friendly. What happens in this tale is that the folk imagination creates a character whose traits befit patriarchal hegemony. The story juxtaposes two contradictory images: an affectionate brother and an apathetic neighbor.

Conspicuously, the woman suffers physically and psychologically due to the outrageous behavior of her brother. Physical violence manifests itself in the loss of both her hands. The pain and misery following such an operation must be inconceivable, especially when she finds herself alone in the forest with nobody to help her. Psychological violence is revealed through her exposure to such a heart-breaking dilemma at the hands of her lovely brother. The brother's behavior is so unjust and merciless. Though his sister took care of him after the death of their parents, his behavior is unanticipated. It is pretty hard to dismiss the impact of this terrible callousness from her mind.

Therefore, this tale represents the monstrousness of the patriarchal society that does not consider the fraternal bonds that bind members of the same family. Brotherhood merits nothing if compared to the image of the male in society. Like the tales collected by Inea Bushnaq, this tale collected by Malika El Ouali Alami validates the same Moroccan cultural norms that accentuate the superiority of men over women. The woman in this tale is obedient, which exposes her to two kinds of violence, physical and psychological. Indeed, the woman's scars have faded away, but her feelings of disappointment are eternal, for her heart is broken forever. Thus, this validation functions by emphasizing the inferiority of women in a patriarchal society governed by male fantasies.

\section{Beautiful Almond Synopsis}

"Beautiful Almond" tells the story of a king who waited a long time to get his first and only child. The girl was so beautiful that he could not give her a name. Therefore, he decided to leave it up to her to choose her name once she grew up. The princess grew and became a lovely and intelligent lady loved by everyone. Yet, her people did not know how to call her. The princess was fond of almonds, so she decided to name herself Beautiful Almond. She refused all wealthy and handsome princes who wanted to ask her hand for marriage. Her cousin tried to tempt her and have her for one night. However, Beautiful Almond made him spend the night with her servant. The following day, he told everyone that he had spent the night with the princess. The princess, however, revealed to everyone that the lady with whom he had spent the night was her servant. The discovery surprised and convinced the prince that his cousin was not an "easy prey to catch" (Alami, 2013, p. 18).

\section{Commentary}

This tale depicts the mentality of the Moroccan patriarchal society. This mentality provides men with the right to do whatever they want while it hampers women. Men can indulge in any activity since patriarchal institutions favor them over women. Such activities can be noticeable all through the tale. The princess is supposed to take care of her purity, whereas the prince is expected to try to seduce his cousin. The Moroccan culture forbids one to have sex before marriage. Yet, if a man indulges in a sexual relationship, his action is not taken seriously, for "after all he is a man," 
goes the Moroccan cliché. However, if a woman cannot be cautious and protect her virtue, she becomes a social outcast. In this way, the way the Moroccan patriarchal society functions is quite paradoxical.

This tale presents two types of violence: sexual and psychological. On the one hand, the prince abuses the princess sexually. He tries everything to have her. After spending the night with her maid, he goes to the palace "to boast about his triumph" (Alami, 2013, p. 18). Sexual violence in this particular instance is demonstrated, first, in attempting to get a sexual act; second, in raping the maid, thinking she was the princess; and, third, in divulging the details of his adventure as if raping the princess, his cousin, were a heroic deed. In addition, the tale contains psychological violence manifested in causing psychological harm to the princess, who is exposed to an agonizing experience at the hands of her cousin, who is supposed to protect her. The impact of this harrowing experience should mark the life of the princess forever. In addition, though the tale does not throw light on the maid's feelings after the sexual abuse she was exposed to, we could ascertain that her heart would be as broken as that of the princess. The maid's experience is worse than Beautiful Almond's.

The exposure of the princess and her maid to these types of violence reveals that Moroccan patriarchal institutions are selective, especially when the issue concerns man's immediate gain. This tale, as the previous ones, validates Moroccan cultural norms. It does so because it emphasizes the position of women as marginalized creatures doomed to remain on the margin forever. What contributes to this position is women's passive stand as they are unwilling to question the workings of the patriarchal society they belong to. Therefore, validating Moroccan cultural norms in this tale emphasizes that a woman is a second-class citizen. Her fate is to submit to man and tolerate his mistreatment even if she is a princess.

Both tales demonstrate that the stories collected by Malika Alami include examples of violence against women. This violence is physical, sexual, and psychological. These types harm the body, the psyche, and the intimacy of the women mentioned in the tales. Indeed, the violence experienced by these women is representative of the one experienced by Moroccan women in reality. Furthermore, both stories seem to validate the Moroccan cultural norm that considers women inferior and unworthy beings, who deserve nothing but indifference and maltreatment in a patriarchal society governed by men, their interests, and their mindsets.

\section{Conclusion}

This examination of four folktales has revealed that gender-based violence is a recurrent theme in Moroccan folktales. Hence, the researcher would reiterate her former claim that Moroccan patriarchal institutions provide a strong impetus for this omnipresence. This is due to two reasons. First, gender-based violence is founded on gender norms that refer to social and cultural norms related to the proper roles and duties of both sexes. These norms initiate men to hostility, hate, and aggression and women to weakness, obedience, and inferiority. This initiation results in a social acceptance of men as dominant and women as dominated. Thus, the socialization of both sexes has ensued in an unequal power relationship between both of them. Second, gender-

Arab World English Journal for Translation \& Literary Studies 
based violence has become an ideological instrument whereby Moroccan patriarchal society legitimates its abuse and marginalization of women.

Concerning the analysis of the previous folktales, it evinces sundry dynamics of and locations vis-à-vis gender-based violence, primarily psychological. These dynamics and sites vacillate between the harsh realities of the human world in "The Foreign Wife" and "Beautiful Almond" and the magic of the supernatural world made of ogres and genies in "The Girl Who Banished Seven" and "The Learned Woman." Therefore, these four tales illustrate the predominance of gender-based violence in Moroccan patriarchal society. Moroccan folklore, whose primary function is to validate cultural and social norms, deftly delineates this predominance.

\section{About the Author:}

Fatima Zahra Touzani is a Ph.D. researcher at Sultan Moulay Slimane University, Faculty of Arts and Humanities, Beni Mellal, Morocco. She has been teaching English at Cadi Ayyad University, Faculty of Sciences, Semlalia, Marrakech since 2019. Her major research areas are: postcolonial studies, modern poetry, and modern fiction. ORCID: https://orcid.org/0000-00019385-2701

\section{References}

Alami, M. E. (2013). Kan Ya Ma Kan: Moroccan Folktales on Women. Marrakech: Afaq.

Bascom, W. (1965). The Forms of Folklore: Prose Narratives. The Journal of American Folklore, 78 (307), 3-20.

Bascom, W. (1954). Four Functions of Folklore. The Journal of American Folklore, 67 (266), 33349.

Bushnaq, I. (1986). Arab Folktales. New York: Pantheon Books.

Krug, E. G., Dahlberg L. L., Mercy, J. A., Zwi, A. B., \& Lozano R. (eds.). (2002). World Report on Violence and Health. Geneva: World Health Organization.

Mackay, F. (2021). Raising Awareness and Improving Responses to Gender-Based Violence: The Contribution of Feminist Thought and Activism. In C. Bradbury-Jones \& L. Isham (Eds.), Understanding Gender-Based Violence: An Essential Textbook for Nurses, Healthcare Professionals and Social Workers (pp. 3-13). Cham: Springer.

Meurens, N., \& Spanikova, H. (2017). Glossary of Definitions of Rape, Femicide and Intimate Partner Violence. Gedimino: European Institute for Gender Equality.

United Nations (1993). The United Nations Declaration on the Elimination of Violence against Women. Geneva: UN General Assembly.

Western, D. (2013). Gender-Based Violence and Depression in Women: A Feminist Group Response. New York: Springer. 